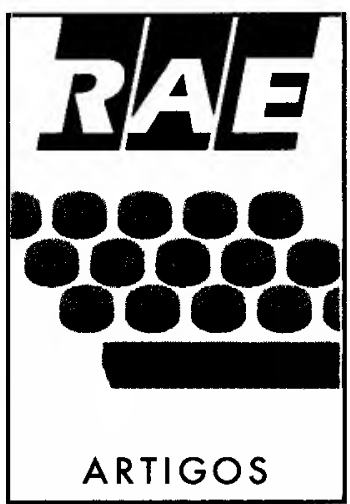

\title{
REENGENHARIA - EM BUSCA DE UMA TEORIA
}

A crescente importância do tema Reengenharia torna premente uma análise mais detalhada de suas origens. Uma teoria que define os conceitos básicos envolvidos e seus pré-requisitos para implementação é apresentada.

The increasing importance of Reengineering needs a theory about its origins. A theory that gives the basic concepts and prerequisites to implementation are explained.

\section{PALAVRAS-CHAVE:}

Base tecnológica, alinhamento

estratégico, estratégia para

tecnologia da informação,

Reengenharia de Negócios,

Reengenharia de Processos.

\section{KEY WORDS:}

Technological base, strategic alignment, Information Technology Strategy, process reengineering, business reengineering.

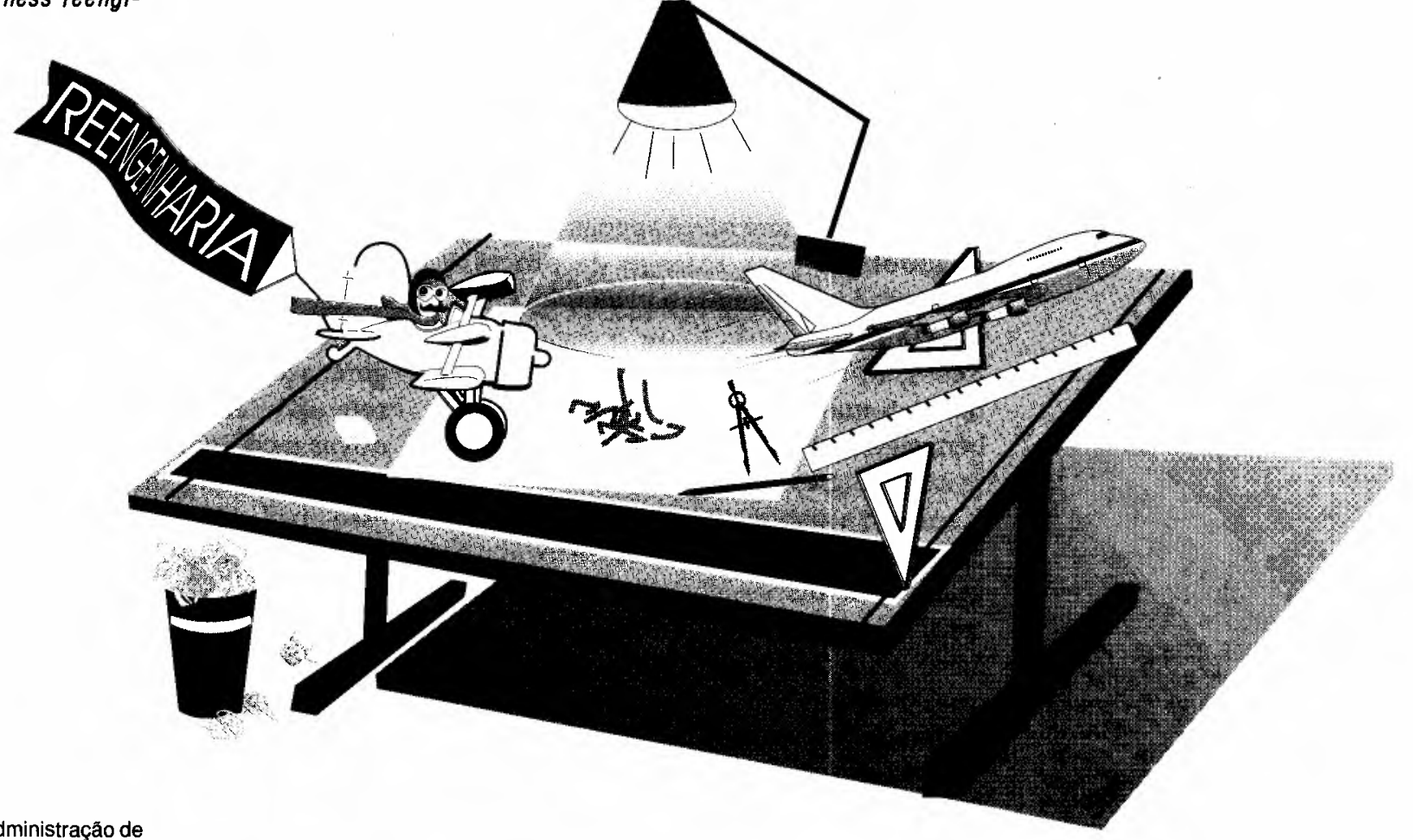

"Mestrando em Administraçáo de Empresas na EAESP/FGV. 
Este artigo visa a trazer aos leitores uma perspectiva de três pontos críticos para uma melhor compreensão da Reengenharia. No primeiro ponto buscamos uma justificativa e a sua origem e, paralelamente, procuramos chamar a atenção para o papel fundamental que a tecnologia tem sobre as organizações, principalmente nos anos 90. O segundo ponto é apresentar aos leitores a ampla dimensão estratégica que a Reengenharia pode e deve ter quando adotada por uma organização, ao mesmo tempo que mostramos os riscos para a organização de um processo de Reengenharia, reduzido em sua extensão, mas ambicioso em termos de resultados. Por último e secundariamente, demonstramos como a Reengenharia se relaciona com as técnicas de melhoramento contínuo como TQM - Total Quality Management.

A Reengenharia pode ser entendida como algo cíclico, que se repete de tempos em tempos na história do homem.

\section{REENGENHARIA — POR QUE AGORA?}

A Reengenharia não é apenas uma nova metodologia para redesign de processo, como pode ser tomada a princípio. Quando Hammer ${ }^{1}$ verbalizou o conceito da Reengenharia no artigo "Reengenharia: não automatize, destrua", esclareceu também algumas das mudanças aparentemente caóticas que estão ocorrendo. Segundo Hammer, a justificativa para a Reengenharia é que a tecnologia da informação atualmente disponivel requer uma estrutura, ou organização, própria para poder

1. HAMMER, Michael. Reengineering work: don't automate, obliterate. Harvard Business Review, p. 110-2, Jul./Aug. 1990. Sua definição é "Reengenharia é o radical redesign dos processos de um negócio para atingir ganhos dramáticos de performance." que, certamente, não é uma estrutura organizacional criada antes do advento dessa nova tecnologia. Hammer, porém, apesar de justificar Reengenharia no contexto histórico, não o faz de forma mais ampla.
Dentro de uma perspectiva mais abrangente, podemos definir a Reengenharia como a busca de uma nova forma de realizar um processo a partir de uma nova realidade tecnológica, para obter a performance "máxima" pelo uso dessa nova tecnologia. Dessa forma, a Reengenharia pode ser entendida como algo cíclico, que se repete de tempos em tempos na história do homem.

A Revolução Industrial, e com ela a economia industrial, teve seu início na segunda metade do século XVIII com a invenção do tear hidráulico e da máquina de fiar. Porém, o processo de transformação que criou a estrutura, ou organização, adequada à nova base tecnológica surgiu somente no início do século XX, 150 anos adentro da nova economia. Os principais marcos dessa transformação foram: os princípios de Taylor na forma de realizar as tarefas; a base da administração dada por Fayol; a linha de montagem criada por Henry Ford (1907) e o conceito de divisionalização da empresa criado por Alfred $P$. Sloan na GM (1920). E, de fato, os maiores ganhos da economia industrial surgiram a partir dessa nova estrutura organizacional que foi amplamente reproduzida por toda a atividade humana neste século.

Partindo dessa constatação, propomos um modelo teórico para tentarmos definir o momento em que a transformação das organizações se inicia por força da tecnologia. Por analogia, podemos imaginar esse processo como uma represa que somente abre suas comportas quando a água atinge um dado nível. Da mesma forma, a alteração profunda da estrutura das organizações somente se inicia quando o desenvolvimento alcançado num grupo de novas tecnologias atinge determinado nível de amadurecimento. Consideraremos esse nível como sendo o momento em que essas novas tecnologias começam a ser utilizadas de forma integrada, formando a base tecnológica de uma nova economia, e que os produtos oriundos dessa integração são colocados à disposição da sociedade de maneira relativamente democrática (baixo custo e fácil acesso).

O processo de desenvolvimento de uma nova economia agora pode ser delineado 
de forma teórica (ver figura 1). Dentro da maturidade da velha economia começam a surgir tecnologias que diferem radicalmente das existentes até então, portanto, de baixa utilidade. Essa fase inicial é seguida por um período de aperfeiçoamento, primeiro integrando as novas tecnologias com as antigas e, num segundo momento, viabilizando o uso conjunto dessas novas tecnologias, formando uma nova base tecnológica. Quando essa nova base tecnológica torna-se disponível à sociedade de forma relativamente democrática, a estrutura organizacional transforma-se, trazendo ganhos de produtividade inimagináveis até então. Esses ganhos de produtividade geram acumulação de recursos que viabilizam o surgimento de novas tecnologias, reiniciando-se o ciclo.

Essa apresentação seqüencial é teórica, pois na realidade essas fases se sobrepõem. Esse conceito fica bem mais claro quando observamos o que está acontecendo com a economia atual.

\section{A ECONOMIA DA INFORMAÇÃO}

A economia da informação, que substituiu a economia industrial, tem como base a eletrônica e consolidou-se nos anos 50 em função de três fatores: a massificação dos meios de comunicação simples, como a TV e o telefone; a utilização efetiva do computador e o início do processo de miniaturização com a invenção do transistor (ver quadro 1 ).

Agora, nos anos 80 e 90, a economia da informação está sendo consolidada pelo uso conjunto de sua tecnologia, ao mesmo tempo que a sua democratização é obtida principalmente pela redução de custos advindos da miniaturização. Portanto, segundo nossa teoria do ciclo da tecnologia e transformação da organização, está se delineando o momento onde uma nova organização deve aparecer. Podemos dizer que não é por coincidência que observamos, dentro da teoria das organizações, quebras de paradigmas e uma avalanche de novas teorias.

Se a transformação das organizações, ou ciclo de Reengenharia (conforme a definição proposta), ocorrida no início do século aconteceu quase de forma natural, o ci-
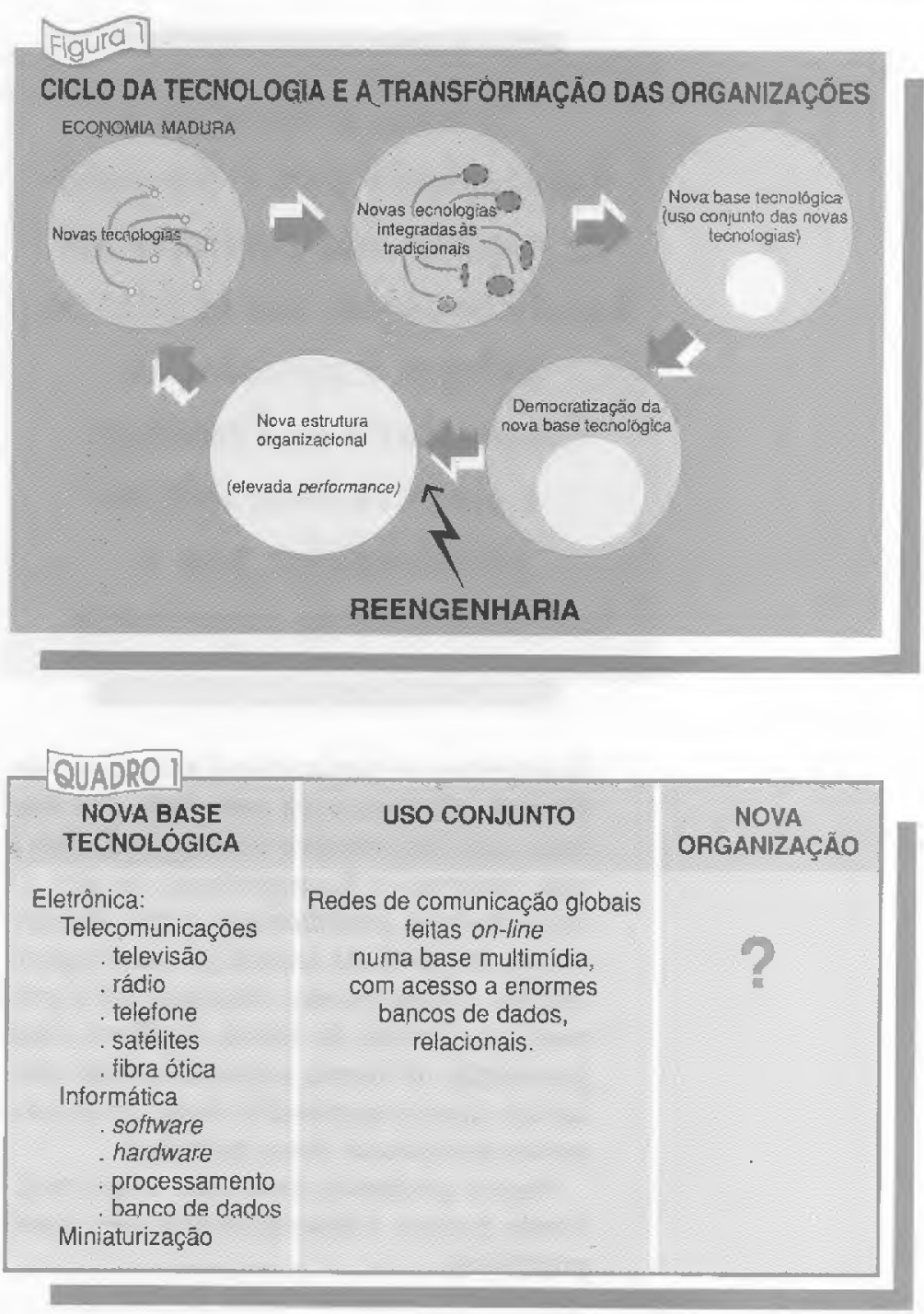

clo atual está sendo bem mais complexo e aparente por duas razões:

- a economia da informação está se desenvolvendo com uma rapidez muito maior que a anterior, em função da maior facilidade para acessar a informação (oriunda da própria tecnologia) e do núvel educacional da população, quando comparado com a situação existente no irício do século;

- o uso conjunto da nova tecnologia afeta diretamente a forma como as organizaçōes trabalham, porque estas se estruturam em função dos fluxos de informação (o que é mais verdadeiro para grandes corporações ${ }^{2}$ ).

A Reengenharia, dentro dessa visão ampliada, representa o ponto de ruptura
2. HOPPER, Max D. Rattling SABRE - new ways to compete on information. Harvard Business Review, v. 68 , n. 3 , p. 118-25, May/Jun. 1990. 
3. HALL, Gene, ROSENTHAL, Jim, WADE, Judy. How to make Reengineering really work. Harvard Business Review, v. 71 , n. 6, p. 119-31, Nov./Dec. 1993. Resultados globais são gastos totais e lucratividade.

\section{- \\ Quando orientamos a Reengenharia para a dimensão do negócio, não perdemos um beneficio sequer dos obtidos no enfoque tradicional ou Reengenharia de Processos, e ainda abrimos imensas possibilidades para a transformação da organização.}

da estrutura organizacional antiga e o surgimento de uma nova estrutura. Na verdade, não importa se o nome que damos a esse processo é Reengenharia ou não. $\mathrm{O}$ importantc ć pcrcebermos a real dimensão do impacto da tecnologia nas organizações. Nesse ponto, Hammer foi o primeiro a colocar, de forma explícita, essa pcrcepção na teoria organizacional, deixando clara a impossibilidade de as empresas escaparem desse processo.

Agora podemos entender mais facilmente porque a Recngenharia tem como premissas:

uso intensivo da tecnologia da informação: afinal, estamos procurando a organização adequada para a economia da informação;

ganhos de produtividade dramáticos: a nova forma de organizar um processo deve trazer resultados impressionantes quando comparados com a forma anterior utilizada na estrutura organizacional da economia industrial;

foco no processo: uma vez que a organização existente está com "destino marcado", devemos focar nossa atenção no negócio que a originou, representado na organização pelo conjunto de processos por ela administrados;

não melhore, inove: qualquer melhoria do processo existente é desnecessária. Melhor será redesenhar de forma radical e fundamental o processo e, então, aplicar técnicas de melhoria e qualidade.
Da mesma forma que devemos creditar a Hammer o reconhecimento pelo resgate da importância da tecnologia na redefinição das estruturas das organizações, temos que admitir que ele não nos forneceu um sistema do que chamou de Reengenharia. Essa falha colocou em risco todo o conceito e o trabalho de outros pesquisadores sobre o tema, trazendo quase um. descrédito, que, a posteriori, foi revertido graças à força de experiências cujos resultados mostraram a consistência dos conccitos que estão por trás da Reengenharia.

Podemos agora discutir sobre as metodologias e o escopo da Reengenharia que atualmente estão sendo apresentadas para as empresas. Não entrarcmos nos detalhes do processo de implantação, mas apresentaremos os principais erros $\mathrm{da}$ abordagem inicial da Reengenharia (Reengenharia de Processos), comparando com uma abordagem mais atual, conhecida como Reengenharia de Negócios (da qual mostraremos somente as principais fases para a sua implantação).

Atualmente, é possivel delimitar duas classificações para projetos de Reengenharia: uma abordagem mais restrita em extensão, chamada Reengenharia de Processos, e uma outra que se propõe a guiar a empresa por um processo completo de transformação, chamada Reengenharia de Negócios.

Resultados de pesquisas ${ }^{3}$ mostram que empresas que obtiveram resultados globais relevantes com processos de Reengenharia adotaram uma postura de total comprometimento com o projeto, deram a mais ampla abrangência possível, buscaram uma clara orientação para o cliente c o mercado, no momento de estabelecer a visão que iria orientar o processo, e consideraram a tecnologia da informação como parte fundamental do planejamento estratégico.

A empresa que decide embarcar num projeto de Reengenharia deve fazer uma série de opções, conscientes ou não, que definem as possibilidades do processo e seu objetivo - ficar restrita a ganhos de 
produtividade, qualidade e redução de custos ou buscar um enfoque que permita a transformação da organização e até do seu negócio. Essas opções ocorrem quando a organização:

- define os objetivos da Reengenharia em termos de custos e produtividade, isto é, de otimização, em vez de objetivos mais amplos como melhoria do relacionamento com o cliente (em todos os sentidos):

- estabelece uma série de projetos independentes de Reengenharia de Processos sem que se apóiem num nítido objetivo, em vez de estabelecer uma visão amplamente divulgada pela organização que direcione e crie sinergia entre os projetos;

- objetiva resultados de curto prazo (um a dois anos), em vez de definir uma perspectiva para cinco anos ou mais;

- possui executivos que não assumem de forma decidida a coordenação de projetos de Reengenharia, limitando-se a uma participação simbólica. A organizaçāo designa alguém para ser o gerente de Reengenharia (como temos hoje o gerente de qualidade total em diversas empresas), em vez de empenhar-se na conquista do entusiasmo e comprometimento de todos (membros da organização, acionistas, clientes, fornecedores etc.);

- faz alterações na infra-estrutura, (sistemas de informação, recursos humanos e estrutura organizacional) de forma desorganizada e conseqüentemente sujeitas a uma série de problemas, em vez de alterá-la de forma integrada e orientando os investimentos para uma homogeneidade organizacional de longo prazo (treinamento, equipamento, novas estruturas etc.);

- define a razão motivadora para a Reengenharia em termos e objetivos de caráter financeiro, em vez de buscar benefícios múltiplos;

- decide que o foco da Reengenharia será restrito nos processos e em escala limitada, e não com toda a organização,

- define o papel da área de sistemas de informação como um órgão de suporte ou assessoria e não como peça central do processo.

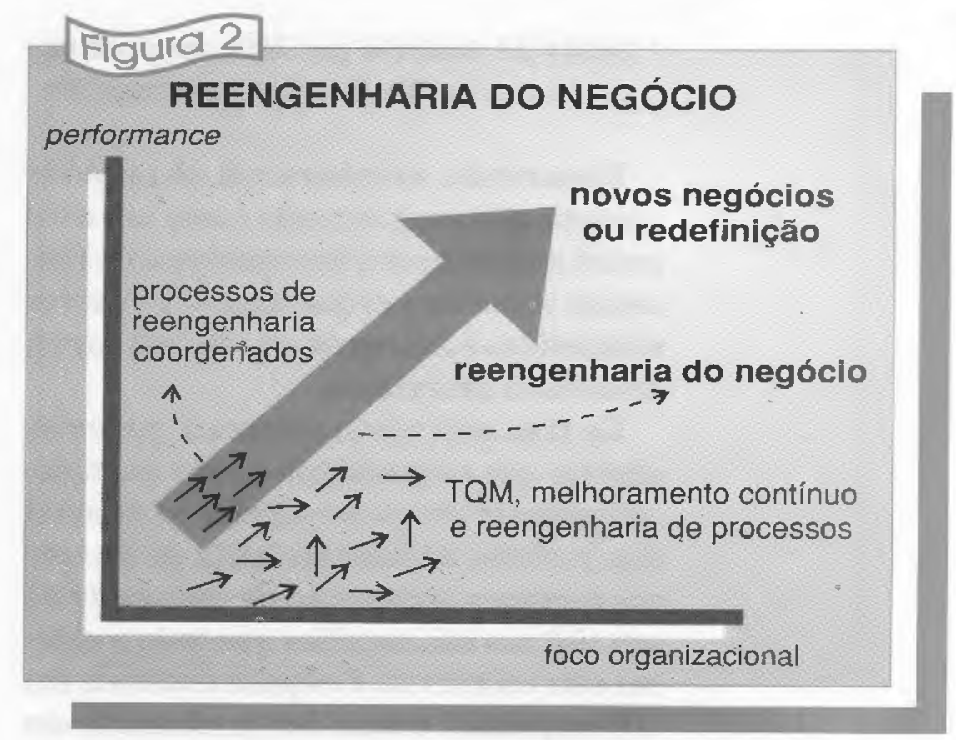

É importante percebermos que, quando orientamos a Reengenharia para a dimensão do negócio, não perdemos um benefício sequer dos obtidos no enfoque tradicional ou Reengenharia de Processos, e ainda abrimos imensas possibilidades para a transformação da organização. Poderíamos comparar esquematicamente a Reengenharia de Processos e a Reengenharia de Negócios (ver figura 2).

A Reengenharia de Negócios reduz a possibilidade de vários riscos existentes na Reengenharia de Processos. Orientações de curto prazo e para resultados financeiros geram, na maioria dos casos, um conjunto de projetos de Reengenharia completamente descoordenados. Embora cada projeto possa trazer resultados dramáticos, a característica descoordenada e fragmentada reduz significativamente a possibilidade de resultados mais amplos e, pior ainda, reduz os resultados sinérgicos que realmente podem ser dramáticos, como a transformação do negócio.

A abordagem descoordenada fragmenta esforços e traz uma série de problemas:

- a existência de diferentes formatos de bancos de dados, diferentes hardwares e softwares, criando incompatibilidade e redundância;

- demissões desnecessárias e necessidade de gastos maiores com treinamento de $\mathrm{RH}$, para atender requisitos diferentes de cada processo, reduzindo a flexibilidade dos membros da organização;
4. Estamos nos referindo ao foco da Reengenharia e não à forma de implementaçāo, que nesse caso é sempre feita através do redesigndos processos. 
- perda de controle por falta de padronização nas avaliações dos processos etc.

Resumindo, simplesmente não se pode garantir que a organização como um todo estará melhor após a Reengenharia de Processos somente porque alguns processos submetidos à Reengenharia apresentaram resultados dramáticos.

De fato, pela teoria sistêmica, podemos afirmar que a organização, como um todo, dificilmente obterá resultados na maioria dos projetos de Reengenharia de Processos porque a otimização de uma parte de um sistema não significa que todo o sistema será otimizado. Pesquisa realizada em 100 empresas ${ }^{5}$, e mais detalhadamente em 20 , mostra que aquelas que fizeram seus processos de Reengenharia de forma mais ampla possivel obtiveram reduções dos custos totais da ordem de $17 \%$, enquanto que as empresas que adotaram uma perspectiva mais estreita tiveram reduções insignificantes (menores que $1 \%$ ). O que deve ficar claro é que a Reengenharia, como tem sido apresentada, orientada somente para o processo, não garante um melhor desempenho da organização, mas do processo, e, às vezes, à custa do resto da organização.

P’orém, a grande vantagem da Reengenharia de Negócios não está apenas em 5. HALL, Gene et al. Op. cit. perspectiva micro, ou de processo. A Reengenharia de Negócios fornece uma base mais sólida para a organização enfrentar as resistências e as barreiras de transição que existem no processo, principalmente por requerer, entre outras coisas, uma sólida base estratégica e comprometimento por parte da alta direção. Na realidade, um projeto estruturado de Reengenharia de Negócios funciona como um verdadeiro break-through driver para a organização durante o processo de transformação.

\section{Reinterpretando a Reengenharia: uma visão estratégica de transformação do negócio}

Uma vez aceita a necessidade premente de uma nova estrutura organizacional de forma a "colocar" a empresa na economia da informação, esta deve ser a meta de qualquer processo de Reengenharia. Ter clara a real dimensão da Reengenharia é o primeiro passo para poder usufruir todas as possibilidades que ela oferece. Algumas empresas que passaram por processos de Reengenharia apresentam resultados impressionantes, muito além da esfera operacional, como novas possibilidades estratégicas e novos negócios, frutos da Reengenharia e do uso intensivo da tecnologia da informação. Processos de Reengenharia sem uma perspectiva estratégica e desatentos às modificaçōes que possam

\section{REENGENHARIA E OUTRAS METODOLOGIAS ORGANIZACIONAIS DE MUDANÇAS}

A Reengenharia não possui uma metodologia consolidada, e ainda está longe disso, apesar de observarmos um rápido delineamento dessa nova metodologia a partir da experiência pioneira de um grande número de empresas americanas e umas poucas brasileiras.

A Reengenharia, como tudo que é novo, pode assumir vários nomes. Ou se preferirem, várias outras técnicas quando aplicadas alcançam resultados similares aos da Reengenharia, como OVA - Overhead Value Analysis, AVA - Activity Value Analysis, CPR - Core Process Redesign etc'. Embora todas essas técnicas possam chegar a resultados similares aos obtidos com a Reengenharia, seu foco é menor e menos ambicioso. O que é importante frisar é que a Reengenharia utiliza todas as ferramentas disponiveis em outras. técnicas para atingir seus objetivos. Isso é especialmente claro em relaçāo ao ferramental dos sistemas de melhoramento contínuo como CEP - Controle Estatístico de Processo, TQC Total Quality Control, TQM - Total Quality Managerneril etc.

Técnicas de melhoramento contínuo, como TQM (Total Quality Management), diferehtemente do que é amplamen-

1. RIGBY, Darrel. The secret history of process Reengineering. Planning Review, v. 21. n. 2, p. 25-7, Mar./Apr. 1993. 
vir a ocorrer na estrutura organizacional podem ser extremamente prejudiciais.

Dentre us diversos modelos e teorias surgidas recentemente sobre Reengenharia, o modelo de três fases proposto por William H. Davidson ${ }^{6}$ é o que, em nossa opinião, melhor consegue englobar todo seu potencial. Nesse modelo, o processo de Reengenharia é composto por três fases, caracterizadas por sucessivas mudanças do foco da organização e dos objetivos perseguidos relativos à performance. Embora Davidson considere fundamental que a perspectiva cstratégica permeie todo o processo de Reengenharia, não julga necessário uma fase inicial na qual a empresa deve concentrar esforços. Porém, acrescentaremos ao modelo essa fase inicial, objetivando o alinhamento estratégico da organização (ver figura 3 ).

Na primeira fase, estratégia, ć realizado todo o processo de formulação do plancjamento estratégico e alinhamento da organização (devendo ser expresso através de uma visão motivadora) para implementação do processo completo de Reengenharia. Nessa fase, são avaliadas a estratégia para o negócio e a tecnologia para a adequação das operações e das estruturas existentes. Na fase II, ativação, uma vez definidos na fase I os processos-chave pela nova orientação, o foco organizacional passa a ser interno, e a atenção volta-

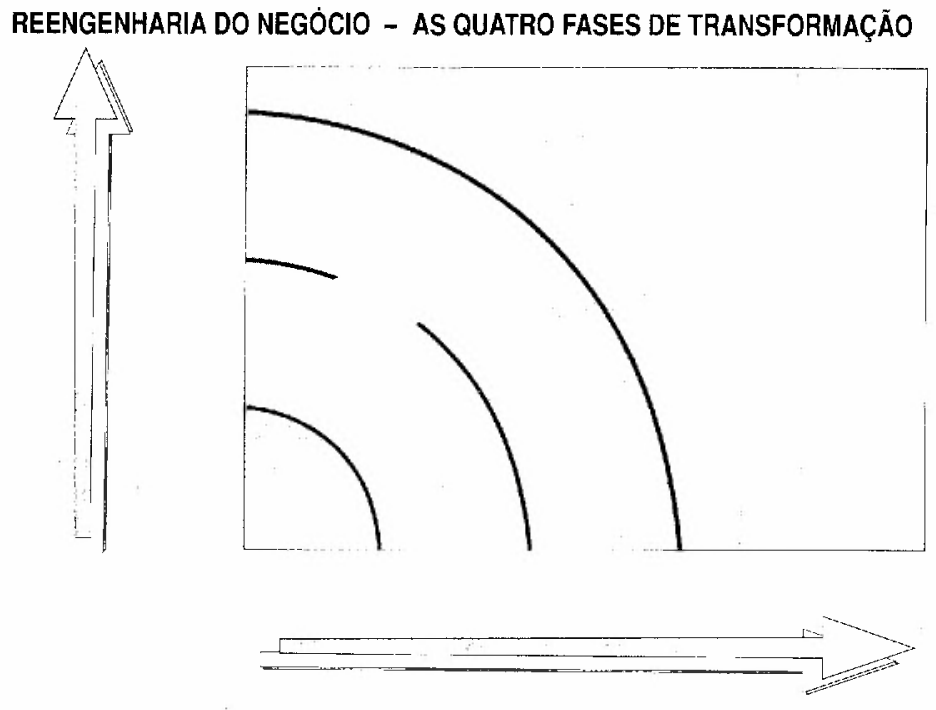

FONTE Baseado no modein de três fases de DAVIDSON, W. H. Beyond Re engineering: the three phases of business transformation, IBM System Journai, * 32. n.1, p 65-79,1993

se para os ganhos de performance relacionados com a Reengenharia de Processos (redesenho e a automação de processos existentes), objetivando o aumento da produtividade e da qualidade e a redução dos custos. Na fase III, melhoria ou ampliação do negócio, partindo das habilidades e da infra-estrutura desenvolvidas nas fase I e II, o foco é transfcrido para a agregação de valor aos processos e serviços oferecidos ao cliente, como nos recebidos junto aos fornecedores. A fase IV, redefinição, envolve a formação de novas unidades de
6. DAVIDSON, W. H. Beyond Re-engineering: the three phases of business transformation. IBM System Journal, v. 32, n 1, p. 65-79, 1993.

te afirmado por alguns especialistas ${ }^{2}$, dificilmente se casam com processo de Reengenharia. A principal razão está nas diferentes premissas e procedimentos (ver quadro 2). Os defensores mais radicais da Reengenharia, como Hammer ${ }^{3}$, afirmam que as técnicas de melhoramento contínuo devem ser aplicadas em un processo somente após se ter feita a Reengenharia do mesmo. Porém estudos de empresas brasileiras que estão envolvidas em processos de Reengenharia de Negócios mostram que a divulgação dos conceitos de qualidade e incentivo a programas de qualidade ajudam o processo. Essa utilização da técnicas de qualidade com a Reengenharia deve ser restrita, pois um fator preocupante referente à inversão da ordem, ou utilizaçāo concomitante de ambos processos, permanece: o comprometimento com os funcionários. Técnicas de mclhoria contínua pressupõem uma forte confiança e a existência de um compromisso de longe prazo entre as partes, que de forma alguma pode ser garantido no processo de Reengenharia ${ }^{4}$. Portanto, é de se esperar que empresas que desenvolveram e obtiveram excelentes resultados através de técnicas da melhoria contínua, enfrentem maiores resistências internas, se adotarem a Reengenharia.

2. Ver DAVENPOAT, Thomas $H$. Need radical innovation and continuous improvement? Integrate process Reengineering and TQM. Planning Review, $v$. 22, n. 3 , p. 6-12, Mayidun. 1993: FUREY, Thimothy, R. A six step guide to process Reengineering. Planning Review, v. 21, n. 2, p. 20-3, Mar./Apr. 1993.

3. HAMMER, Michael. The Reengineer. Planning Review, v. 22, n. 3. p. 18-21, May/Jun. 1993. (Entrevista concedida a Robert M. Randall.)

4. Não queremos dizer que a Reengenharia é parceira de demissōes em massas, como muitas afirmam. Na verdade, demissóes em massa săo advindas de processos de Reengenharia sem arientaçāo estratégica bem definida. 


\section{REENGENHARIA}

Infra-estrutura
Difusão / Orientação

Forma de melhoramento

Compromisso e determinação dos executivos seniores

Impacto organizacional

Tecnologia
- Normalmente requer um novo design.

- Vai contra alguns símbolos e valores da cultura existente.

- Implica criar um comprometimento com a mudança, porém as possibilidades para uma nova cultura devem ser mantidas abertas.

- Top-town.

- Horizontal (processo) elimina as fronteiras entre funções e entre a empresa e os clientes e fornecedores.

- Total e efetivo (pelo menos $50 \%$ do tempo).

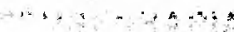

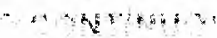

\section{MELHORAMENTO CONTÍNUO}

- Raramente é necessário alterar a presente forma.

- Implica criar uma nova cultura organizacional baseada no comprometimento mútuo entre as partes.

- Bottom-up.

- Horizontal (processos), porém respeita as barreiras verticais entre funções, e por isso, é voltada para tarefas.

- Relativo ou simbólico (por ser um processo controlado e restrito, 0 compromisso dos altos executivo pode ser baixo).

- Muito alto.

- Normalmente requer novas tecnologias (principalmente $\mathrm{Tl}$ tecnologia da informaçâo).

\section{Necessidade de recursos}

- Elevada, tanto em capital (tecnologia), como em treinamento.

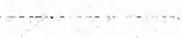

- Baixo (não altera significativamente a estrutura).

- Sendo o método utilizado o melhoramento contínuo, não requer necessariamente novas tecnologias.

- Baixa, a maior parte destinado a treinamento.

- Baixa.

- Totalmente integrada.

- Fragmentada.

- Baixa dificuldade, é um processo controlado e fragmentado. intensas e abrangentes.

- Coordenação estratégica e crítica

Resultados

- Produz resultados radicais, pode levar ao surgimento de novos negócios.

- Zero defeitos e a perfeição do status quo (incremental).

1. HALL, Gene et al. How to make Reengineering really work. Marvard Business Review, v. 71, n. 6, p.119-31, Nov./Dec. 1993. Neste artigo os autores mostram claramente a necessidade de um compromisso total do malor executivo da empresa (CEO) com 0 processo de Reengenharia, chegando explicitamente a estabelecer o percentual de, no minimo, $50 \%$ (p. 128).

to

Embora alguns casos possam afirmar que aplicaram com sucesso processos de Reengenharia e TQM concomitantemente, quando analisamos seus exemplos normalmente um (mais provavelmente ambos) dos seguintes fatos estava presente: ou o processo de Reengenharia era feito dentro de um foco muito estreito, ou a cultura organizacional necessária para obter todo o potencial das técnicas de melhoramento contínuo não estava plenamente desenvolvida. 
negócios, pois o aperfeiçoamento dos processos e serviços ocorridos na fase III levam a organização a se defrontar com a possibilidade de criar novas unidades de negócios independentes. As capacidades desenvolvidas através das fases anteriores são "orientadas" estrategicamente no sentido de tornarem-se novas competências centrais ou core competences ${ }^{7}$, podendo redefinir a atividade original da organização. Portanto, a fase IV implica uma revisão estratégica do plano original apresentado na fase I.

\section{Fase I}

Nessa fase a organização já deve romper com as tradicionais formas de agir $e$ adequar-se para a mudança. O foco organizacional deve se centrar na busca de uma nova direção estratégica e na avaliação do negócio. Nesse ponto, é crítico o reconhecimento da tecnologia da informação - TI - como força determinante de todas as atividades da organização. É fundamental que a organização abandone a percepção tradicional da tecnologia da informação. Hoje, a TI permeia e determina todas' as atividades humanas e não pode mais estar restrita a um departamento, a um plano diretor de informática ou a qualquer coisa parecida. A organização deve reconhecer a transcendência da TI, deixando de vê-la apenas como um suporte para estratégias de negócios e aceitando o fato de a TI ser também uma força modeladora das estratégias dos negócios existentes e determinante de novos negócios.

O planejamento da utilização da TI deve passar pela análise detalhada dos aspectos-chave de sua formulação estratégica: prever usos combinados da TI com a tecnologia da atividade da organização; ter uma perspectiva envolvendo não apenas a empresa, mas os seus relacionamentos com o ambiente; realizar previsões de longo prazo para as principais tecnologias que afetam o desempenho e desenvolver uma "visão tecnológica" para a organização.

Como modelo de planejamento para unir a estratégia do negócio com a estratégia da TI, tanto na formulação como na implementação, sugerimos o modelo de

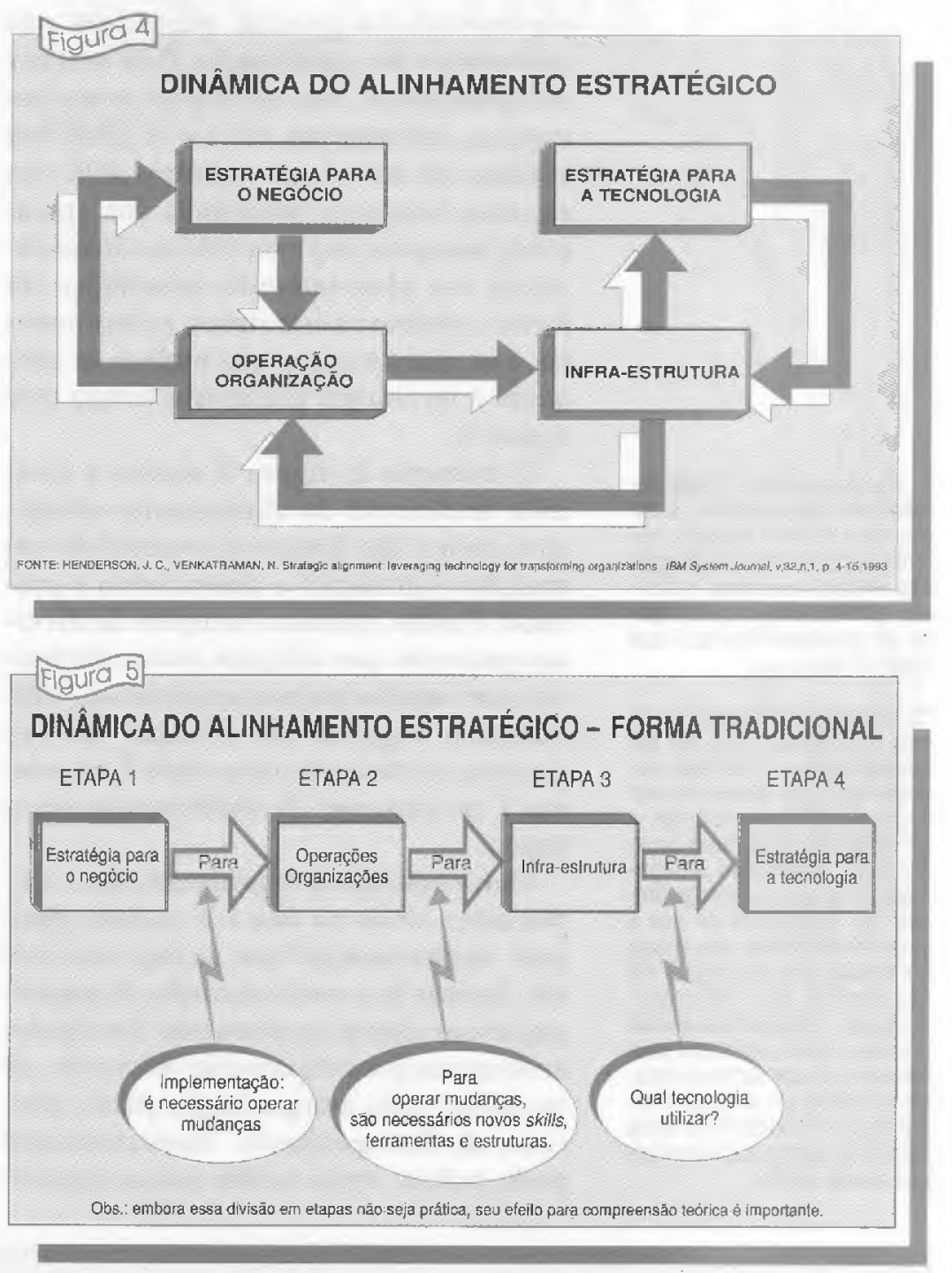

Henderson e Venkatraman ${ }^{8}$, que além de envolver a TI no processo de planejamento estratégico e implantação, traz a interdependência entre as componentes estratégicas, como mostra a figura 4 (ver figura 4). Vale a pena ressaltar que o modelo proposto tem como pressupostos a adequação estratégica, isto é, o inter-relacionamento entre os componentes ambientais e internos é consistente (possui strategic fit); e que essa adequação estratégica é contínua e dinâmica para adaptar-se às mudanças ambientais sempre que for necessário.

Basicamente o modelo proposto mostra a complementariedade entre as partes que formam a organização e sua estratégia. Por exemplo, a definição da estratégia do negócio pode ser o primeiro passo para o alinhamento estratégico, porém, para im-
7. Competência central ou core competence pode ser definida como a capacidade de empregar de forma harmónica todas as forças e habilidades da empresa para explorar vantagens competitivas construir uma poderosa posiçăo de mercado. Outra forma de definir core competence é: tecnologia + organização social + aprendizado coletivo. Sua essência e característica básica é ser amplamente compartilhada por todos dentro da organização. Ela deve: ser uma fonte de diferenciação significativa, ter um amplo espectro de aplicaçōes para o desenvolvimento de vantagens competitivas, funcionar como um elo de uniấo entre os negócios da organizaçáo e ser difícil de ser imitada pelos concorrentes.

8. HENDERSON, J. C., VENKATRAMAN, N. Strategic alignment: leveraging technology for transforming organizations. IBM SyStem Journa', v. 32 , п. 1, p. 4-15, 1993. 


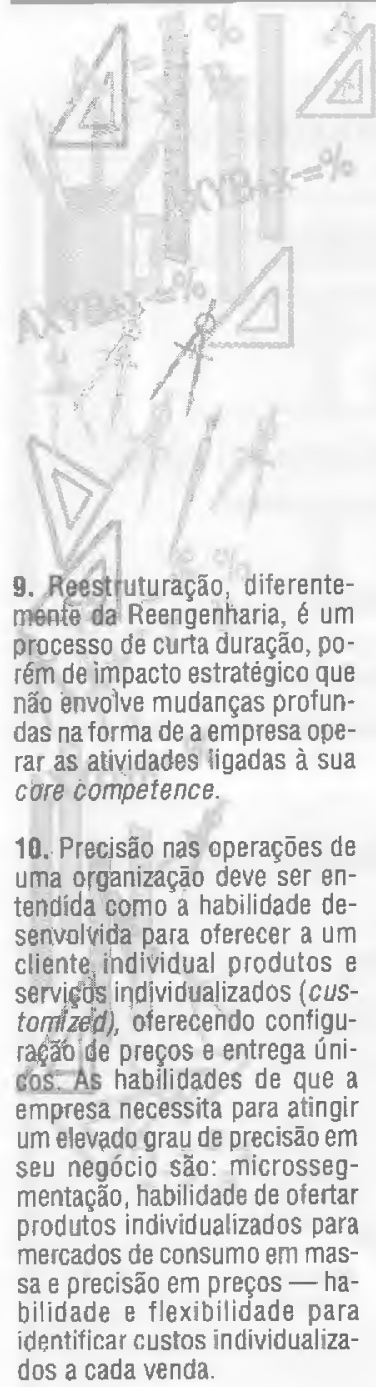

plementá-1o, é preciso mudanças nas operações e na organizaçấol Para realizar essas mudanças, são necessários novas estruturas, ferramentas, no que se refere aos sistemas de informação, e outros skills (em recursos humanos, tecnologia das operações), mas para implementá-los são necessários um planejamento estratégico de forma a definir as estruturas, as ferramentas e os treinamentos que melhor se adequem à tecnologia presente e futura (ver figura 5).

O exemplo da figura 5 mostra a dinâmica tradicional do alinhamento estratégico, onde a alta direção faz o papel do formulador estratégico e desencadeia o processo. Porém, existem exemplos de diversas empresas que utilizam outras dinâmicas, com resultados mais expressivos. Ressaltamos aquelas que colocam estratégia para a tecnologia como etapa 2, ou mesmo 1 , no processo de alinhamento estratégico.

Outra ação que a organização deve empreender, ainda na fase I, é realizar qualquer reestruturação ${ }^{9}$ que se faça necessária. Apesar de a reestruturação de organizações ser algo já amplamente divulgado, lembramos que esta deve ser feita antes de se alinhar toda a organização para o processo de Reengenharia. Reestruturação pode incluir, entre outras coisas, consoli- dações, mudanças estruturais, terceirizações e desinvestimentos em negócios que não pertençam à core competence atual. A razão para se realizar a reestruturação é evitar que a empresa aplique seus esforços de Reengenharia em áreas que não tenham perspectiva estratégica.

A organização já deve finalizar a fase I com a difusão do alinhamento estratégico e de uma visão clara e positiva do futuro da organização pelos seus membros e pelos grupos com que se relaciona.

\section{Fase II}

A fase II é a busca da excelência operacional através da Reengenharia de Processos. Essa fase se inicia com o mapeamento e posterior redesign dos processos existentes buscando a redução de custos, aumento da qualidade e da produtividade. Nessa fase, a organização deve buscar a excelência em cinco dimensões operacionais: produtividade, velocidade, qualidade, "precisão"10 e serviço ao cliente.

As três primeiras dimensōes são características da fase II, e, não por coincidência, são os objetivos mais comuns observados em experiências de Reengenharia. Precisão e serviços ao cliente são objetivos bem mais complexos e são considerados como os focos iniciais da fase III. Entretanto, as empresas que buscam incremen-

\section{AMERICAN AIRLINES - UM EXEMPLO PARA AS QUATRO FASES DE TRANSFOHMAÇÃO}

A AMR, empresa holding do grupo da American Airlines, vem transformando por completo a si mesma, e todo o setor de transporte aéreo comercial nos EUA a partir do desenvolvimento de seu sistema de reservas por computadores - SABRE. Três fatores levaram a AMR a um processo completo de transformação do negócio: a evolução do SABRE, de um modelo de automaçäo simples para um sistema integrado de múltiplas funçốes; a desregulamentação do setor aérco comercial americano e a visẫo dos altos executivos da organização.

O sistema SABRE começou a operat no mercado americano em 1963, após quatro anos de desenvolvimento, objetivando uma maior eficiência através da automação no processo de reserva de passagens e assentos. A princípio, esse sistema não era visto como estratégico, mas como uma forma de manter paridade com a concorrente United Airlines. O objefivo era reduzir custos e erros na emissão de reservas (produtividade e eficiência).

Em 1980, em meio à crise gerada pelo processo de desregulamentação do setor comercial aéreo, a empresa foi obrigacta a rever seus paradigmas e buscar uma nova perspectivà estratégica. Nesse momento, a empresa passou por um extensivo planejamento estratégico, caracterizando a fase I, iniciando a transformação do negócio. A direção da empresa percebeu que o sistema de reservas por computador passaria a ser central para a conquista de espaço nas agências de turismo e, conseqüentemente, no mercado.

Nessa situação, inicia-se a fase III (a AMR não necessitou passar pela fase II, uma vez que o sistema SABRE já era continuamente aperfeiçoado por uma questão concorrencial), onde o S.ABRE passa a sér melhorado, com o objetivo de oferecer novos serviços e produtos às agências, de forma a torná-las quase dependentes da AMR, pela qualidade insuperável 
tos em produtividade, velocidade e qualidade orientadas para o cliente, possuem maiores chances de atingir a fase III com menores resistências ${ }^{11}$.

Essa fase se caracteriza pelos seguintes programas: uso intensivo de técnicas de mapeamento de processos; redesign (redefinição e automação) dos processos, objetivando aumentos da produtividade; utilização do ferramental de TQM e controle estatístico de processo, para incremento da produtividade e estabelecimento de medidas; e just-in-time, time based competition e EDI - Eletronic Data Interchange, para ganhos de velocidade.

\section{Fase III}

Quando a organização busca resultados na precisão e serviços ao cliente, surgem, inevitavelmente, o aumento na oferta de produtos e serviços e a abertura de novos mercados para a empresa. Pode-se dizer que a fase III de transformação inicia-se quando o foco da organização muda explicitamente da otimização das operações internas para a busca da satisfação do cliente c ampliação dos mercados, através da excelência na precisão do negócio, nos serviços ao cliente e no desenvolvimento de novas core competences.

Essa fase se caracteriza pelos seguintes instrumentos: grupos de foco, pesquisas

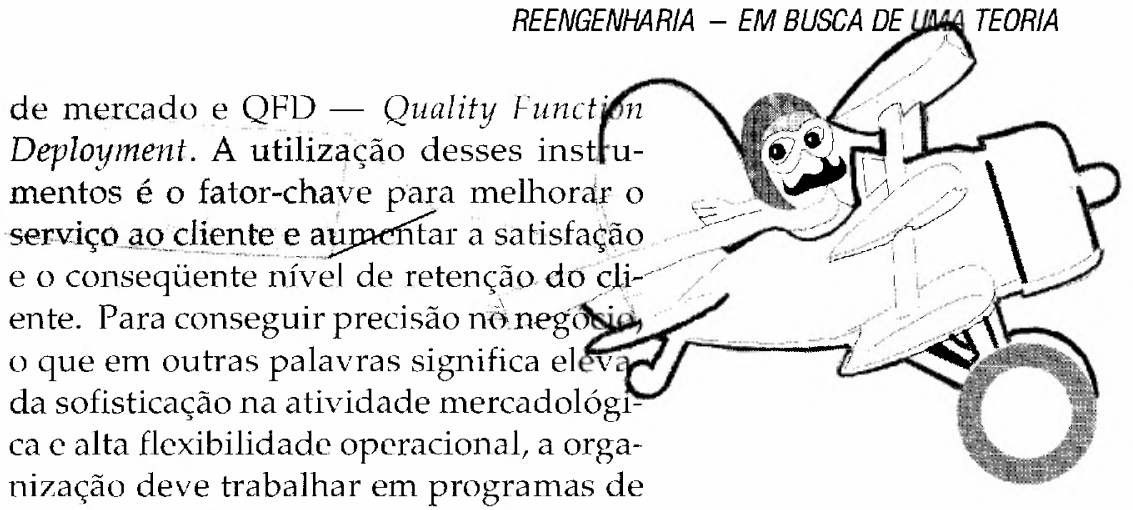

mass-customization, microssegmentação e sistemas de custeio flexíveis.

$\Lambda$ plena aplicação dessas técnicas normalmente gera a ampliação de serviços e produtos oferecidos pela organização. Por isso, a empresa deve estar aberta e alerta para ampliar seu escopo de mercados e de novos clientes. O ideal seria que a entrada em novos mercados e o acesso a novos segmentos já estivessem previstos no planejamento realizado na fase I. Portanto, programas que objetivem a ampliação dos canais de distribuição e comunicaçấo, dos mercados e o estabelecimento de parcerias passam a ser centrais nessa fase.

\section{Fase IV}

A emergência de novas unidades de negócios (SBU - Strategic Business Unit) caracteriza a quarta fase do processo de transformação. É importante notar as opções estratégicas dessa fase. Uma nova
11. Conforme podemos observar no box Algumas experiências brasileiras.

do seu sistema de reservas. Entre esses serviços, destacam-se uma versão mais amigável ao usuário, chamada EAASY SABRE c SUPER SABRE, o formecimento do board pass antecipado, a ampliação das escolhas do cliente etc. Uma mclhoria estratégica foi abrir um canal diretamente ao consumidor final, através do acesso ao sistema EAASY SABRE em redes de computadores como Prodigy (network de serviços pessoais interativos). Em 1988, o sistema SABRE contribuía com $6 \%$ da receita da AMR, porém, já era responsável por $17 \%$ do lucro de 801 milhões de dólares gerado pclo grupo.

A partir de 1988, sob pressão de uma possível ação anti-truste do Congresso Americano, que levaria a AMR a perder o controle sobre o sistema SABRE, a empresa decidiu partir para outros negócios. A opção da AMR por outros mercados não visava apenas à redução do risco de uma intervenção governamental. A real possibilidade de ganhar dinhciro com a nova core competence era mais atrativa que tentar mantê-la restrita ao negócio original da empresa.

A AMR iniciou um programa de diversificação: redefinindo o SABRE com o conceito de "supermercado eletrônico para viagens", ampliou seus serviços e negócios, caracterizando a sua entrada na fase IV do processo de inovação. O sistema passou a incluir hotéis, trens, aluguéis de carros, pacotes de turismo, bilhetes para shows etc. Nessa fase, esses serviços foram ligados à uma nova subsidiária, a AMR Info. Service Inc. - AMRIS. Os objetivos da AMRIS eram procurar reduzir a dependência do sistema SABRE a um único mercado e buscar formas para operar dentro de uma perspectiva global. Através de alianças estratégicas, a AMRIS vem descmpenhando com sucesso sua missāo. Com o Hilton e a Marriott (cadeias de hotéis) e a Budget Rent-A-Car (empresa de locação de carros), a AMRIS desenvolveu um sistema

\footnotetext{
1. Esse exemplo toi baseado em dois trabalhos: o primeiro, um paper preparado pelo professor W. Davidson: Transforming computer reservation service - the evolution of an info-business in the airine business (Redondo Beach. CA: Mesa Research, 1992), 15 páginas; o segundo, um arligo publicado por Max D. Hopper (vice-presidente sênior para IS na American Airlines e vice chairman para a AMR Information Service), Ratttling SABRE - new ways to compete on information: Harvard Business Review, v. 68, n. 3, p. $118-25$, Mayijun. 1990

(Continua na página seguinte)
} 


\section{AVALIAÇÃO DE EXPERIÊNCIAS BRASILEIRAS EM REENGENHARIA}

Fase I Fase II Fases III e IV

Agroceres: velocidade (reduziu o tempo entre a emissão dos pedidos e o faturamento de catorze para sete dias).

Banco de Boston: serviços ao cliente (busca a automatização de operações básicas, orientadas pela visão "o cliente pode ser atendido sem sair de casa" oriunda de um plano estratégico estruturado).

Climax: velocidade (modificou o processo de distribuição de mercadorias, diminuindo de dez para cinco dias o atendimento de pedidos).

Grupo Machine: produtividade (centralização dos serviços de suporte, travendo economias de US\$ 18 milhôcs ao ano).

RMB - Refinações de Milho Brasil: velocidade (redução de todos os lead-times da empresa visando a melhorar desenvolvimento de produtos, distribuição e produção. Houve também uma extensa revisão do mix de produtos).

Santa Crux: serviço ao cliente (reestruturação e informatização do atendimento ao cliente).

Não está claro se essa elapa foi ou não concluída.

Reengentaria aplicada apenis a um processo.

Reengenharia pode atingir toda a organizaçăo (a extensāo é delerminada pela estratégia que originou o processo).

baixa possibilic
do ncócio.

do negocio.

do negocin.

são e microssegmentação.

Essas novas core competences podem ser percebidas como essenciais para o negócio tradicional da empresa e por isso serem resguardadas, mesmo oferecendo possibilidades de novos negócios. Por outro lado, se a revisão estratégica demonstrar a viabilidade em explorar comercialmente essas novas core competences, a Reengenharia termina por levar a uma verdadeira transformação do negócio original da organização.

Os programas principais para os quais a empresa irá voltar sua atenção nessa fase são: atividades de start-up, consolidação, desenvolvimento do espírito empreendedor e busca de alianças estratégicas para acelerar a exploração das novas competências.

\section{Algumas experiências brasileiras}

Em artigo publicado na revista Exame $^{12}$ no ano passado, uma série de exemplos são apresentados como modelos de Reenge-

revisão estratégica de toda a organização deve ser a primeira tarefa nessa fase. Novas competências surgem do desenvolvimento de uma alta capacidade em utilizar a informaçăo de forma a gerar valor e que se traduzem em mass-customization, preci- nharia. Como mostra o quadro 3 (ver quadro 3), a maioria dessas empresas, com exceção do Banco de Boston, da RMB e da Santa Cruz Seguradora, pelo teor das colocaçōes de seus representantes, deixa clara a restrita orientação de scus pro- mais com menos. Axame azer $52-9,4$ de agosto de 1993 Também foram feitas entrevistas e acompanhadas palestras dos executivos de parte das empresas citadas.

computadorizado de reservas e gerenciamento para o mercado de redes de hotéis e locadoras de carros; com o maior sistema de reservas europeu, a AMRIS levou seus serviços aos viajantes europeus; e em associação com o sistema nacional de ferrovias francês, está criando um sistema de reservas para toda a Europa.

A partir de 1989, outras empresas foram abertas para aproveitar a nova core competence da AMRIS: a AMR Direct Market Co., que fornece serviços de telemarketing para o grupo AMR e outros clientes; a AMR Technical Trainning, que oferece treinamento em produtos que envolvam automação e sistemas; a AMR Video Financial Services, que atua em serviços de video banking e cobrança para instituiçóes linanceiras; a AMR Freight Automation, que fornece softwares para transportadoras de carga a AA Decision Technology, que vende todo o know-how desenvolvido em TI e sistemas de informações - SI - para as empresas.

Em 1990, mais de $80 \%$ da compra de passagens já cra feita através de sistemas de reservas por computador em agências, contra $40 \%$ em 1976, transformando completamente o perfil do mercado. O sistema SABRE possuía um porte invejável: continha 45 milhões de passagens em seus bancos de dados, relacionadas a 650 empresas aéreas, com um crescimento em torno de $50 \%$ ao ano, nos últimos 15 anos. Por outro lado, esse sistema representou um investimento acumulado de US\$ 1,3 bilhões.

Como previsto pela direção da empresa, em 1990 a AMR ofereceu mais de $50 \%$ do sistema SABRE à venda ao preço de US\$ 15 milhões para cada percentual de ações, o que totalizava US $\$ 1,5$ bilhōes como valor de mercado para o sistema. Porém, a oferta não incluiu a AMRIS e tudo o que se relacionava com a core competence em desenvolver e comercializar serviços de informaçāo. 
cessos de Reengenharia para os resultados advindos da fase II, obtendo melhoria restritas aos processos que foram submetidos à Reengenharia.

$$
\text { 7. } ., i s
$$

A Reengenharia não é uma opção para as organizações, é um imperativo imposto pela nova base tecnológica. Todas as organizações irão passar por esse processo, de uma forma ou de outra, c podemos prever que muitas ficarão pelo caminho, enquanto outras que trabalharem duro para guiarem a si mesmas serão recompensadas num curto espaço de tempo.

Claro que as grandes mudanças que estão ocorrendo em outras variáveis ambientais influenciam a organização, como a globalização e o acirramento da competição, o amadurecimento do consumidor, a busca da qualidade etc. Por outro lado, vale a pena perguntar: até que ponto a transição para a nova base tecnológica é responsável ou não por essas mudanças? Feito isso, é possível ver onde a tecnologia da informação pode ajudar a organização a lidar com essas variáveis ambientais.

O mais importante, porém, é a necessidade de uma nova forma de relacionamento com os empregados c com todos os grupos ligados à organização. São esses grupos que levarão a cabo qualquer projeto de Reengenharia (principalmente os empregados) e que devem ser a força criativa que determinará o futuro da organização.

Três sugestões para futuros trabalhos podem ser feitas para o desenvolvimento da teoria da Reengenharia de Negócios: a integração das outras teorias para abordar a mudança organizacional (teorias sobre o papel da cultura na organização etc.); $o$ desenvolvimento de éstudos para avaliar o impacto da tecnologia da informação na relação homem-trabalho e a aceleração do processo de desenvolvimento do ferramental e das técnicas orientadas para os conceitos básicos da Reengenharia.

Esses estudos são muito importantes, pois, como podemos observar no nosso dia-a-dia, a Reengenharia está em rápida evolução e espera-se, para um futuro não muito distante, uma nova evolução do conceito. A Reengenharia de Negócios deve evoluir para a Reengenharia da Ca- deia Produtiva, que passaria a buscap ganhos não apenas dentro da empresa, mas envolvendo toda a linha produtiva que forma o setor industrial em que a empresa está inserida.

A Reengenharia é algo novo dentro da teoria organizacional mas, diferentemente de outras proposições que apareceram, tem por trás de si um conceito sólido que a justifica. Independentemente do nome dado, a Reengenharia requer uma teoria séria que a valorize. Esse é, de fato, o objetivo deste artigo.

\section{COMENTARIOS SOBPE OEFMP}

Um ponto importante que deve ser salientado são as diferenças das opções atuais e as encontradas pela pioneira AMR no desenvolvimento de seu SI. Hoje, ao contrário da AMR, as empresas dispōem de diversas facilidades, que com certeza aceleram o processo e diminuem seus custos:

- hardware: hoje, a variedade de direções e opções existentes em tecnologia da informação sem dúvida permite às empresas "customizarem" a tecnologia às necessidades específicas. conseguindo maior eficiência;

- software: o SI da AMR foi por muito tempo, desenvolvido por ela própria (desenvolvimento in-house), o que tornou o processo lento e caro. Hoje, parcerias e contratação de empresas especializadas aceleraram significativamente o processo;

- know-how: as experiências de empresas como a AMR e outras em diversos setores estão facilitando c acclerando os processos de desenvolvimento de SI e a metodologia para conduzir o processo, baseada na Reengenharia.

O caso dramático de transformação do negócio lornecido pela AMR deve servir como exemplo para as empresas que queiram assumir a liderança em seu setor de forma duradoura e, ao mesmo tempo, lançar a empresa definitivamente na economia da informação.

Hoje, pode-se dizer que a estrutura da AMR está mais próxima à de uma empresa integradora de sistemas como a EDS, que de uma companhia aérea, o que leva a AMR a ponderar em passar o controle da American Airlines para seus empregados, a exemplo de sua concorrente United Airlines ${ }^{1}$. A mudança do negócio (e da core competence), como ocorreu com a AMR (atualmente considerada benchmarking mundial em gerenciamento de sistemas de informação ${ }^{2}$ ), deveu-se a aspectos conjunturais (pressões do governo e o declínio do negócio de transporte aéreo comercial) e ao pioneirismo que permeou todo o processo. Portanto, deve ficar claro que a mudança na core competence é sempre uma opção estratégica.

1. KELLY Kevin ef al. The airlines to labor: buy in - or get bashed. Business Week, International Edition, n. 3360-660 p. 40 , Nov. 1,1993 .

2. Mc GOUGH, Robert. Best-practice companies: AMR. Financial World, v. 160, p.37-8. Sept. 17, 1991 